\title{
Infrastructure for Sustainable Development and Management of Water Resources
}

\author{
MY Zainudeen
}

\begin{abstract}
The entire water world is entering an era in which increasing competition for water supplies, growing risk of water pollution \& environmental degradation, and increasing social, economic and environmental costs of developing water resources are prominent, posing sustainability threats, especially in developing countries. Developing and managing of water resources in a sustainable manner is complicated due to the irreplaceable nature of water in human life, economic development and environmental protection, and to a wide range of stakeholders involved in it. The importance of developing, conserving and managing water resources, especially with respect to sustainability, productive use and environmental protection poses many challenges to the water professionals and managers today, highlighting the necessity of a new look on this sector.
\end{abstract}

Sustainable development of water resources emphasizes many concepts; withdraw less than what could be produced/replaced, maximize positive (economic) benefits and minimize negative (social and environmental) impacts, protected eco systems, should not create a situation for future generations to compromise on water needs and so on. Infrastructure has been developed for water resources in Sri Lanka since the pre Christian era, especially for irrigated agriculture. Since then the sector has evolved through millennia but the sustainable management and its effects on other development sectors have not been properly studied or evaluated in the light of future implication that this sector has to face. Successive Governments which came to power, one after the other, in the post independent period have taken many positive steps in implementing new water related infrastructure development projects yet the sector has not reached a sustainable status as far as the productive use of water and the environmental protection and user satisfaction are concerned.

Generally, the term infrastructure in the water sector implies construction of some diversion, structure, intake, reservoir, canals, tunnels etc., in a traditional way. But in the present context, the term "Infrastructure" means a lot, much more than physical structures constructed on the ground. One has to assure whether these are founded on firm policies, designed and constructed in a user friendly and environment friendly manner, appropriate managements and mechanisms are in place for allocation of water, operation and maintenance of the systems and so forth. In some cases these infrastructure demands certain legal Compliance which are required to satisfy social aspects as well. Therefore, the term Infrastructure needs to be viewed through a set of new dimensions which constitute many factors influencing its sustainability.

It is intended to discuss some of the salient issues connected with the design, and implementation of infrastructure projects for the sustainable development and management of water resources, in this paper, giving due consideration to water conservation, and watershed and environmental protection as well.

\section{Introduction}

Economic growth and prosperity of any nation largely depend on the available economic infrastructure which facilitates the day to day life of the people to be more productive through active and efficient participation in their livelihood activities and social life. Infrastructure development is as old as mankind and has evolved through millennia, having always captured the attention and high priority of the rulers and governments. Conceptual philosophy and objectives behind any particular infrastructure have not changed very much with time but the technology, impacts and the management have changed drastically from era to era.

Eng. MY Yainudeen, PC Dip in Engineering, (Moratuwa),M Sc (Hon. (Ireland). C Eng., I Eng., FIESL, FIIESL, Currentlyfunctioning us the Deputy Chief Secretary (Eng. Services), North Westerm Pronincial Conmcil. 
Sri Lanka, being a country blessed with considerable water resources, has been the leader in developing water resources through known history of a few millennia in the region. The ancient irrigation works that were constructed prior to the Christian era hold testimony to these but, unfortunately, details of the design concepts and the management models used are not available today. However, it is evident that these systems have been designed, constructed, operated and maintained in an environment friendly manner in order to accrue the anticipated benefits which have been realized successfully.

Sustainability of developing and managing water related infrastructure faces many challenges and threats due to the drawbacks and shortcomings in policy frameworks \& legislation, regulatory measures, planning, design \& construction and management. Lack of awareness, capacity building and sense of ownership among the water users as well as lack of political will and commitment among politicians also contribute a lot to constrained sustainability of these systems. Apart from the above, support and commitments of the civil society, private sector organizations and policy makers are very much important in securing sustainable development and management of water related infrastructure. Water management must be considered as everybody's business, since everybody in the basin/society is a stakeholder, directly or indirectly.

The benefits that could be accrued from water related infrastructure largely depend on the uninterrupted functioning and effective performance of the system as envisaged at the planning stage. Also the success of such a system depends on the supporting water resources policy frame work and established legal measures (Foundation), appropriateness and usage of physical structures (hardware) and the associated management models (software).

\section{Water Resources Development in Sri Lanka}

\subsection{Irrigation Development}

The new era of water resources development commenced in the 1930's as a new agricultural policy came into effect, in which irrigation has been the predominant element. Since then, a number of irrigation and settlement projects were constructed in the dry zone of Sri Lanka until recent times. Consequent to the introduction of the open economic policy in the country in 1977, the country's economic development direction took an important turning point. The thrust of the changes was in the direction of reducing government interventions and allowing the market forces to guide the pattern of economic activities. However, in this regime too, public investment in the irrigation sector received top most priority. During this period the Mahaweli development project was already under implementation on a phased out mode but it was declared as the Accelerated Mahaweli Development Project (AMDP), the largest multipurpose water resources development project, in that configuration, having a number of large reservoirs constructed for irrigation and hydropower generation.

The main objectives behind these projects were food production towards self-sufficiency and employment generation and reducing population pressure in the wet zone. The irrigation schemes that were developed have brought the area irrigated from the early 1960s to 2000s, under major irrigation schemes from 200 to 480 thousand hectares, while that in the minor irrigation sector has remained fairly constant and the rain-fed agriculture has recorded a decline.

Pumped irrigation systems too were developed as a complementary activity in most of the irrigation projects in order to cultivate high priced crops. Ground water also has been tapped especially in small-scale farming, to supplement surface water in minor irrigation schemes, especially in the dry (Yala) season. High rates of return, socially as well as privately, on investments in agro-wells and pumps have encountered their rapid diffusion, making the private investments as major options in phase III of irrigated agriculture. Large potentials exist for diffusion of agro-wells and pumps in irrigation schemes (Kikuchi M et al, 2003).

\subsection{Urban \& Rural Water Supply}

The National Water Supply and Drainage Board is the principal agency responsible for planning. Developing, commissioning and maintaining 
water supply schemes to provide pipe borne water facilities to the public. Also, it is the state agency responsible for investment in this sector. They extract water from the main rivers, reservoirs and deep wells, at appropriate locations. There are around 500 water supply schemes operated in the Island, out of which 330 are classified as urban. The National Water Supply \& Drainage Board operates 287 of the urban water supply schemes and the respective local authorities operate the rest. The Board produces and distributes $135 \mathrm{MCM} /$ day. In some cases the board supplies bulk water to the local authorities, which in turn distribute the water to the public, collect the water charges and pay for the bulk supply.

About $30 \%$ of the total population and $70 \%$ of the urban population are served with pipe borne water with a level service ranging from $14 \mathrm{hrs}$ to $21 \mathrm{hrs}$ a day. In the urban areas stand posts are provided for the people living in the slums, shanties and other semi-permanent dwellings, in order to meet their bare minimum water needs. However, only about $15 \%$ of the rural population is served with pipe borne water and the rest rely on rivers, streams, lakes and ground water bodies.

Ground water plays the main role in fulfilling the water needs of the community in the rural and urban suburbs, at a low cost by means of open dug wells and tube wells with a coverage of over $80 \%$. Thousands of open dug wells constructed across the country provide the basic drinking water and domestic water needs of the rural population adequately. With the increasing population in the rural and urban suburbs over the last few decades, the demand for water has gone up tremendously.

\subsection{Industries}

C'onsequent to the new industrial development programme associated with the open economy policy in 1977, the manufacturing industry has been identified as an important and strategic sector to realize economic development, aiming at employment generation, regional development, and foreign exchange earnings, etc.

Accordingly, many industrial parks have been established during the last three decades in the Greater Colombo area, Koggala, and in many other locations. Then majority of these parks are established in the vicinity of perennial surface water sources in the western province (wet zone) and draw their water requirement from the Kelani Ganga, Kalu Ganga and Maha Oya while the rest obtain from ground water sources. Also, many industrial parks have been established in the North Western, Sabaragamuwa and Central Provinces recently bordering the Maha Oya, Kelani Ganga and Mahaweli Ganga respectively. Once these industrial parks commence work in full capacity there could be problems pertaining to water allocation in the basins during the low flow period.

\section{National Water Policy Objectives}

\subsection{Irrigation}

In the modern era of agriculture, successive governments, following the footsteps of the ancestors, have taken large measures in the post independent era to improve the country's food production to meet the demand for its increasing population. In this context the term "self sufficiency in food" has been associated in policy documents as well as in the policy manifestos. The term "Food Security" has come into the literature in the recent past subsequent to the introduction of open economy polices and as a result of the globalization process. The prominence of agriculture is well illustrated in the Report of National Policy Framework for agriculture, land and forestry (Ministry of Agriculture, Land and Forestry, 1995).

This is further reinforced by the diversified agricultural policies adopted by the government in the recent past, in an integrated manner. The new agricultural policy spans a vast area covering environment, biodiversity, infrastructure development, agricultural research and transfer of agricultural and other technologies, input management, and crop diversification, domestic \& international trade, and so on. Agricultural policy has been aided by a healthy environmental policy being adopted by the Ministry of Environment and Natural Resources (CBSLAR, 2002).

\subsection{Water Supply and Sanitation}

The Government of Sri Lanka set up the National Policy of Water Supply and Sanitation 
(2002). The major goals of the water supply and sanitation sector, in line with millennium development goals, are to ensure access to clean drinking water and adequate sanitation for all by 2025 . The sub goals are

- to provide access to clean and adequate drinking water to $85 \%$ of population through pipe borne, borehole wells, protected dug wells, protected spring systems and rainwater by 2010 and $100 \%$ by 2025

- $\quad$ to provide piped water supply to $100 \%$ of the urban population and $75 \%$ of the rural population by 2010 at an affordable price while improving the service levels and quality standards to achieve national standards in urban and rural areas

- to provide adequate sanitation facilities to $82 \%$ of the population through pipe borne sewerage, pour flush latrines, ventilated improved pit latrines, dry composed type (Ecosan) by the year 2015. The details of such policies are given below.

- Meet the demand for water supply services from the economic sectors such as industry, tourism, commerce and other related uses

- Encourage and facilitate local government institutions and community organizations, to undertake water supply services, sanitation facilities and waste management systems and their operation and maintenance

- Prepare plans combined with surface drainage and storm water management at catchment area level or river basin level and promote using them

- Encourage and facilitate community participation where appropriate to implement urban development plans and water supply services

\subsection{Current Legislation}

There are a large number of Acts, Ordinances and other forms of Enactments; passed (more than 20) long ago for development, allocation, regulation, usage and management of water resources, in a number of water use sectors. Many of them are either outdated or far too limited to address the issues and problems in the current context of the water use sector. Out of these, Irrigation Ordinance $(1900,1946)$, Mahaweli Authority Act (1978), National Water Supply and Drainage Board Act (No 2 of 1974), Central Environment Act (No 47 of 1980), amended acts Nos 56 of 1988 and 53 of 2000 and Agrarian Services Act $(1978,1991)$ are the most important legislations, as far as water resources conservation, development and management are concerned. Implementation responsibility of the Irrigation Ordinance is vested with the Irrigation Department and the District Secretary, the Mahaweli Authority Act is with the Mahaweli Authority and the Agrarian Services Act is vested with the Department of Agrarian Services.

Traditionally, the operation, maintenance and management of irrigation schemes have been the responsibilities of the farmers, who select a Tract Leader (Vel Vidane, generally a land owner cultivator and often a respected traditional leader) to supervise water deliveries, assign routine maintenance and minor repair works and resolve disputes. His services have been generally appreciated in kind. The responsibility of the Government Agent (District Secretary) was largely confined to arrange cultivation meetings (Kanna Meeting), which constitute the legal binding to resolve delivery disputes and problems pertaining to land matters. One important fact in Sri Lanka, as far as irrigation water is concerned, is it is given free of charge to the farmers.

Recognizing the importance and the urgent necessity of beneficiary participation in irrigation management, since early 1980s, the Government of Sri Lanka is seriously committed to implement the concept of beneficiary participation in all phases of irrigation projects designs, rehabilitation, operation, such as, maintenance and management. Subsequently, in 1989, Government approved participatory management as a policy; accordingly the Agrarian Services Act was amended in 1991, in order to grant official recognition to farmer organizations.

It is clear from the above that the country does not have an updated, comprehensive water resource policy incorporating all water use sectors. Some of the legislative enactments related to water use sectors are more than half a century old and deserve revision and updating to suit the current needs in the sector. 
Having realized this situation, the Government of Sri Lanka established the National Water Resources Secretariat in 1996, with Technical Assistance received from the Asian Development Bank, Food and Agriculture Organization of the United Nations, and the Government of Netherlands, in order to prepare the National Water Resources Policy.

Accordingly, the Water Resources Secretariat has studied the issues concerned in the entire water use sector and prepared the National Water Resources Policy and Institutional Arrangements, which has received the approval of the Government in the recent past. This was a timely decision taken by the Government, in order to put the allocation and management of water resources in a more rational and perspective direction. The study has considered all the issues pertaining to water resources (both surface and ground) and given a detailed policy including the framework, objectives, scope, policy principles and strategies. A considerable dialogue between the policy makers, water users and the environmentalists went on for quite a long time and at last an Interim Water Resources Council was established to implement the recommendation made by the National Water Resources Secretariat. However, this arrangement could not continue due to various political pressures and subsequently funds made available for this purpose has been withdrawn and the interim arrangements have been temporality suspended.

\section{Sustainable Development of Water Resources}

The strong link between water resources and agriculture, forestry, torrential and aquatic ecosystems and urban development, does not permit anyone to degrade the water quality and to misuse available water resources which would impose a major threat to the health and development possibilities of the population in the country, even in the areas with abundant water resources. Present life style changes and aspirations, including significant increases in the Standard of living and per capita income, continued rapid population growth, industrial development, agricultural trends and increased urbanization - all demand higher water consumption in the decades to come. This requires close attention to water resources planning issues and to adopt sustainable development, production and consumption patterns.

The main principle behind the sustainable development of water resources is that the rate of withdrawal both from surface and ground water sources should not exceed the rate at which the source is renewed and its extraction must not jeopardize the biodiversity of the ecosystem. Sustainable development means, continued performance of a given development project delivering the desired benefits at least during the designed project life with minimum or no adverse effects on the ecosystem, environment and the related sectors. Too often, the economic and social benefits of the projects are given higher prominence but their interrelated adverse environmental impacts are not always fully considered during the planning stage. Environmental and development activities must be fully integrated and closely coordinated in order to ensure that the development is sustainable. Water resources come from systems which include rivers, lakes, wetlands and aquifers, their planning and management must therefore be considered in association with their functions in the hydrologic cycle and their interactions with physical, chemical and biological processes in terrestrial ecosystems.

Sustainable development of any infrastructure depends on many factors which are part and parcel of the geographical location concerned. Socio economic status of the people, culture, religious belief, attitudes, topography of the area, available resources etc. are some of them. Also, sustainability depends on the planning fundamentals; design principles, and the mode of implementation employed in developing the infrastructure. The concept of sustainable development seed needs to be sown at the onset of conceiving a project and applied at the planning stage so that the appropriate design concepts could be employed in designing the project. This is a comprehensive optimization process of all the inputs in order to accrue the desired benefits and to minimize the adverse effects in all other sectors.

\subsection{National Water Resources Policies}

Preservation of the integrity of the natural water resources system and provision of water and water related services to the public in an 
economically efficient, equitable, environmentally sound and sustainable manner using an integrated approach for planning and management are the essential elements of a national water resources policy. A natural water resources system represents all the components of the hydrologic cycle (precipitation, evaporation, surface run-off, ground water flows and the physical components such as water bodies, soil, biota and atmosphere) and therefore, policies for protection, preservation, development, usage, water quality monitoring and management of water resources shall be based by incorporating these phenomena.

National policies shall include provisions for assessment of water resources, surface as well as ground water inclusive of the aquifer characteristics and their recharging potentials, incorporating major land and water ecosystems. Also, the policies shall recognize the fact that the water needs are based on multiple purposes and hence the management policies shall pay due attention to capture the complementaries and to reduce competition and identify trade offs among uses in the natural system. Policies must specify that the water resource planning integrates environmental impact assessment including the effects of development on aquatic and terrestrial eco systems, on humans and on the environment. An equitable and justifiable allocation policy among various water user groups shall be implemented based on the needs arising from socio- economic, economic and geographical conditions. A strong regulatory body needs to be established to ensure that socially acceptable water allocation policies are implemented.

National water policies must clearly specify the institutions responsible for implementing different components of the water policies, their responsibilities and the coordinating mechanisms. All the above could be summarized as follows

(a) Policy objectives which describe the major goals

(b) Policy frame which includes

(i) Assessment of Water Resources

(ii) Allocation Policies \& trade off options

(iii) Pollution Control Measures and environmental protection (c) Legislation and

(d) Institutional Arrangements for developing, allocating, regulating, managing and conflict resolving.

\subsection{Planning fundamentals \& approach}

Since water plays an important and irreplaceable role in every sphere of life, protection and sustainable development of water resources require an eco-systemic approach and adequate knowledge and appraisal of linkages with environmental and socio-economic issues. First, there is a need to understand the nature and the bio-geographical implications of water resources at national, regional and local levels. Second, there is a need to recognize the cause-effect relationship between the environmental issues and the development of water resources for socioeconomic development.

This necessitates a water resource development policy to promote a multi-sectoral and multidisciplinary approach to integrated water resource planning and management that optimizes the interests of the environmental protection and sustainable socio-economic development. The requirement of multidisciplinary approach is based on the fact that the sustainable development and management of water resources involves many disciplines such as engineering, economic, social, health, environmental, legal and political, and other disciplines related to water resource development and management. Also, it involves a large number of stakeholders (Politicians, Development Agencies, Administrators, Local Government heads, Environmentalists, user groups, beneficiaries both direct and indirect, etc.)

\subsection{Engineering Design Principles}

Engineering Design Principles of water related infrastructure should be primarily based on simplicity, reliability, adoptability and overall cost effectiveness. Complicated designs and sophisticated equipment must be avoided as far as possible. In addition, once the system is implemented and commissioned it must be easily operable with least maintenance expenditure, service deliverable as planned and must be acceptable to all the stakeholders with least adverse impact on the environment. 
Design of a water related project should pay due attention to three components of the Infrastructure, ie. Protection \& conservation infrastructure, water use (withdrawal, diversion, storage, regulation, distribution etc.) Infrastructure and water quality monitoring Infrastructure.

\section{Sustainable Management of Water Resources}

Sustainable Management of already developed water resources is very important because, on the one hand, an intensive capital investment has already been made and the system cannot be allowed to get ruined and, on the other, that the beneficiaries are eagerly waiting to receive the anticipated services. This involves a large number of stakeholder groups as well as a wide range of physical and environmental diversities and needs input resources such as human, financial and physical. The main functions in managing water resources are operation and maintenance which underpin the major portion of the sustainability issues of the physical systems. Poor operation and maintenance is one of the mostly and widely spoken causes which has lead to many conflicts among the water users, stakeholders as well as severe damages to the physical system in many cases.

\subsection{Operational Aspects}

Most of the irrigation and water supply infrastructure in Sri Lanka are designed and constructed for manual operation which need constant supervision and monitoring in order to ensure that the operational activities are carried out in time to avoid any un-desirable consequences and service deliveries are attended timely, adequately and reliably in an efficient manner. It may not be in the near future in Sri Lanka that the irrigation systems will be modernized incorporating automated operational facilities but some of the water supply schemes which are designed and constructed presently do accommodate this. The idea behind incorporating automated operational facilities should be merely based on improved and efficient operation helping for sustainable management, not merely because of the availability of such a facility. In some cases inappropriate design and inferior construction have caused operational difficulties resulting in delays of service deliveries as well as damages to the structures.

Also, sustainability depends on the operational policies adopted in each case, whether they are firm and flexible, formulated to ensure improved service deliveries, the safety of operators and the infrastructure and are objective oriented. Operational policies shall be formulated for each system separately considering the objectives, socio-economic and topographic conditions, availability and deployability of resources (human \& physical). Blue print operational policies may not be very useful for a given system but this has been the common approach, leading to many disasters.

\subsection{Maintenance}

The major reason behind the collapse/failure of many infrastructures has been poor and/or deferred maintenance. Eroded dams, overgrown canals, leaking reservoirs \& pipes malfunctioning regulating structures \& equipment are not very strange in our infrastructure projects. Inadequate planning, constraint on resources, lack of commitment of the maintenance crew etc. lead this situation. The end result of these defects is wastage of very precious developed/treated water allowing the consumers/crops, and consequently the nation, to suffer. Every infrastructure project should have its own maintenance scheduling and budgeting, staff details and an updated maintenance programme. It should be noted that any works identified under maintenance need to be closely monitored and attended to as scheduled leaving no room for accumulation. Under normal conditions no maintenance works shall be postponed.

\subsection{Stakeholder Participation}

Stakeholder participation has a long history stretching back to the ancient times in many countries where the importance of this phenomenon has been recognized and legalized; this, for irrigation sector, by establishment of farmer organizations. The same concept is practiced in the water supply sector by forming water user associations. The most important aspects of these organizations are conflict resolution, decision making, efficient service delivery, timely and efficient operation \& maintenance leading towards the sustainability of the infrastructure. 


\subsection{Capacity Building}

Capacity building (Institutional and human resources development) in the organizations which are committed for managing water related infrastructure is the major software that could accompany them to success. It is true that most of our organizations recruit appropriately qualified personnel to man the activities and they do possess an organizational structure designed to attend to their works. What is lacking among many of them are the internal cohesion and integration, motivation, training, appreciation and rewarding. Decentralization of management and devolution of responsibility are the keys to increased reliability, coupled with training and technical support. Since the entire world is continuously subject to changes it is not possible for these small organizations to function in isolated cubicles. They also under go these changes willingly or unwillingly. Strategies must be developed and implemented to incorporate these changes for the benefits of the organizations in achieving its goals.

\section{Sustainable Water Related Infrastructure}

Traditionally, diversion structures, reservoirs, dams, canals, treatment plants, pipe networks etc. are considered as water related infrastructure, on the safe assumption that the upstream and down stream conditions of a particular structure would be static, which will never be. In the real sense, these are the water use infrastructure for a given purpose, but the term water related infrastructure, in the context of sustainable development and management, covers a wider scope including water conservation and water shed protection infrastructure and water quality monitoring infrastructure. Also, these infrastructures should be founded on firm National Water Resources Policies and sound management practices in addition to durable physical structures for completeness.

National Water Resources Policies referto a range of political, social, legal, economic and administrative systems which support the development and management of water resources, and delivery of water services, at all levels of society in a sustained manner. This necessarily includes policy objectives, policy frame, legislation andinstitutional arrangements.

The most important component of the water related infrastructure is the management system, called software, live wire of sustainability of the developed infrastructure. It is a subset of the nation's creation of physical and institutional infrastructure, and is much connected with maintaining social justice, equity and cooperation. Very large, productive infrastructure has gone unproductive, beyond repair, even to the level of collapse due to poor operation, maintenance and management practices. The management infrastructure systems (software) of the entire physical infrastructure (hardware) need to be interlinked and integrated in order to assure sustainability. All the components of the infrastructure are shown in the diagram below.

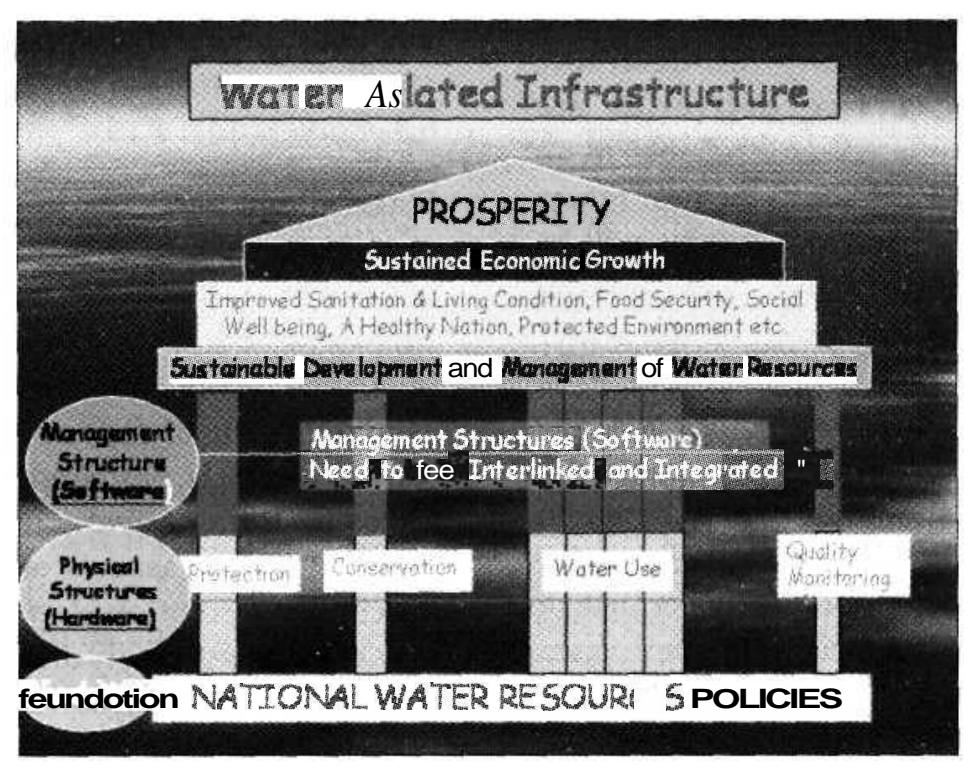




\section{Conclusions}

Sustainable development and management of water resources depends on a range of legislative, political, social, economic and administrative systems that are in place in the country. A clear policy framework, supported by appropriate legislation is foremost and vital for the sustainability in this sector. Provisions must be made in the policy framework and in the legislative enactments that any water resources infrastructure development project need to be complete with water protection and conservation infrastructure, water use infrastructure, water quality monitoring infrastructure and water management infrastructure which include not only the physical structure but also the legal structure as well as the management structure. Properly established regulatory bodies should function under the purview of the apex water resources ministry in order to ensure that the objectives of the National Water Policies are effectively realized and the development programmes are implemented adhering to the conditions laid down at the planning stage and as given in the Project Appraisal Document.

Water management is concerned with political social and economic organizations and institutions which are important for developing and managing water resources. Since water use itself, within the society, is a complicated affair, developing, allocating and managing it equitably and efficiently, and ensuring environment sustainability requires a comprehensive periphery where the voices of all parties are heard and respected in making decisions over the common water. Although the issues raised in any given water sector crisis mostly fall into the technical and economic sphere, the main driving force behind the scene is local politics. Sustainability of water resources management needs the combined commitment of the Government Institutions (National, Provincial and local), various civil groups, particularly at local level as well as the private sector.

Integrated water resources planning and development based on comprehensive ecosystem assessment, taking full account of the use of water in human activities should therefore be the main principle behind the environmentally sound, sustainable development and management of water resources. Integrated water resources planning has two principle goals; one is that to plan environmentally sound development programmes, which are economically efficient and socially acceptable and the other is to implement projects which are sustainable over a long period of time irrespective of the continued availability of external financial or technical assistance.

Further, a much needed action is to create awareness among the water users (irrigation, domestic, industry etc.) on the current status of this sector, economic aspects of water resources development, scarcity of capital, diminishing nature of freshwater resources, adverse consequences of wasting developed water and, more than anything, the cost of not having water when it is needed. This needs to be fostered by the government organizations, non government organizations, civil society, private sector and even the religious organizations. Water crisis must be given equal publicity as that for an energy crisis.

Although the water resource is becoming an economic commodity it must be treated as a social, cultural and environmental resource by giving due considerations to the pervasive values which have existed for millennia, because water is the life of the world and there is no substitute for it.

\section{References:}

1. Asano, T (2001), "Water from Water, Closing the cycle", Stockholm Water Front, Swedish International Water Institute, Stockholm.

2. Biswas, A K et al, "Water for Sustainable Development in the 21st century", Water Resource Management Series, Oxford Press

3. Brohier RL (1979). Ancient Irrigation Works in Ceylon, the Ministry of Mahaweli Development, Colombo, Sri Lanka

4. Central Bank of Sri Lanka, Annual Report, 2002,

5. Hagebro, C et al, (2001), "People and Water Ethics and Goals in the light of Sustainability", Stockholm Water Front, SIWI.

6. Kikuchi et al, 2002, Irrigation Sector in Sri Lanka, Recent Investment. Trends and the Development Path Ahead, IWMI, Colombo 
7. Water Resources Council \& Secretariat, (2000). National Water Resources Policy and Institutional Arrangements, Colombo.

9. Zainudeen, M Y (2001), Water Resources Engineering and Management for Rural Communities, the Challenges for Agriculture, and other Water Users in Sri Lanka In the 21st Century, "Engineer" IESL, Colombo.

10. Zainudeen, M Y (2005), Strategies to Address the National Food Security and Environmental Sustainability In The Context Of Changing Climate And Global Trade Rules. "Engineer" IESL, Colombo. 